\title{
Cardiovascular characteristics of patients initially diagnosed breast cancer
}

\author{
Zhaoying Dong ${ }^{1}$, Fan Zhang ${ }^{2}$, Qiaojuan Huang ${ }^{1}$, Zhaojun Liu' ${ }^{1}$, Siyu Chen ${ }^{1}$, Tao X X $^{3}$, Jun Xiao ${ }^{3}$,
} Changhong Zhang ${ }^{2}$ and Xiaoli Zhou ${ }^{1 *}$

\begin{abstract}
Objective: We aimed to explore the cardiovascular characteristics of patients who were initially diagnosed with breast cancer.

Methods: A total of 600 patients who were diagnosed with primary breast cancer were included in this retrospective study. The data of fasting blood glucose, total cholesterol, total triglyceride, high-density lipoprotein cholesterol, lowdensity lipoprotein cholesterol, lipoprotein (a) (LP (a)) and serum uric acid were collected. Univariate analysis was used to evaluate the cardiovascular risk factors (CVRFs) in patients with breast cancer. The arteriosclerotic cardiovascular disease (ASCVD) risk assessment was performed. Multivariate analysis was used to identify the factors that influenced axillary lymph node metastasis (ALNM).
\end{abstract}

Results: Compared with the premenopausal group, the prevalence of overweight/obesity (47.6\% vs. 35.2\%), diabetes (12.8\% vs. $4.3 \%)$ and hypertension (49.7\% vs. $26.3 \%)$ were significantly increased in the postmenopausal group $(p<0.05)$. Comparisons of rural patients and urban patients showed that there were significant differences in the diagnostic age (49.94 \pm 9.92 vs. $52.59 \pm 11.13)$ in the rural patients was notably younger in comparison with the urban patients ( $p<0.05)$. However, the number of menopausal patients ( $44.3 \%$ vs. $53.3 \%)$ in the rural group were decreased in comparison with the urban group ( $p<0.05)$. In ASCVD risk stratification, the proportion of low-risk patients $(56.4 \%$ vs. $90.8 \%)$, medium-risk patients ( $20.6 \%$ vs $0.3 \%$ ) and high-risk patients ( $19.3 \%$ vs. $6.6 \%)$ were significantly different between the postmenopausal group and premenopausal group $(p<0.05)$. Residence (OR 0.735; 95\% Cl 0.516-1.046; $p=0.087$ ), the number of children (OR 1.250; 95\% Cl 0.990-1.578; $p=0.061$ ) and $L P(a)$ of $\geq 500 \mathrm{mg} / \mathrm{L}$ (OR 0.603; 95\% Cl $0.342-1.063 ; p=0.080$ ) were independent influencing factors of ALNM.

Conclusion: Postmenopausal patients have more CVRFs and higher risks of ASCVD than premenopausal patients initially diagnosed with breast cancer. There was a correlation between CVRFs and ALNM in patients with breast cancer.

Keywords: Breast cancer, Cardiovascular risk factors, Axillary lymph node metastasis, Initial diagnosis

\section{Introduction}

Breast cancer is the most common malignant tumor among women worldwide. It is currently estimated that there are approximately 1.6 million new breast cancer

\footnotetext{
${ }^{*}$ Correspondence: zhouxiaoli_dr@yeah.net

${ }^{1}$ Department of Cardiology, The First Affiliated Hospital of Chongqing

Medical University, 1 Youyi Road, Yuzhong District, Chongqing 400000, China

Full list of author information is available at the end of the article
}

cases worldwide in 2012 [1]. However, the incidence and mortality rates vary substantially, and the 5-year survival rate can reach $85 \%$ to $90 \%$ in the well-developed regions of the world [2]. It has been reported that patients with breast cancer have a significantly increased risk of cardiovascular disease (CVD) in comparison with the healthy controls [3]. The mortality rate of elderly breast cancer patients due to the complications of CVD and cerebrovascular disease is as high as $15.9 \%$, which is higher than that due to the recurrence of breast cancer (15.1\%) [4]. original author(s) and the source, provide a link to the Creative Commons licence, and indicate if changes were made. The images or other third party material in this article are included in the article's Creative Commons licence, unless indicated otherwise in a credit line to the material. If material is not included in the article's Creative Commons licence and your intended use is not permitted by statutory regulation or exceeds the permitted use, you will need to obtain permission directly from the copyright holder. To view a copy of this licence, visit http://creativecommons.org/licenses/by/4.0/. The Creative Commons Public Domain Dedication waiver (http://creativeco mmons.org/publicdomain/zero/1.0/) applies to the data made available in this article, unless otherwise stated in a credit line to the data. 
CVD has become the main cause of death in breast cancer patients [5]. Cancer and CVD have entered into a 'clinical overlap' era [6].

The patients with breast cancer who also have cardiovascular risk factors (CVRFs) are more likely to develop drug-related cardiovascular problems after chemotherapy with anthracycline [7]. Additionally, radiotherapy and chemotherapy significantly increased the incidence of CVD and mortality of patients with breast cancer [8]. Therefore, it is necessary to understand the cardiovascular status before treatment. At present, there are many problems in most studies on CVRFs of patients with breast cancer at home and abroad, such as a lack of clinical data and incomplete data acquisition. Therefore, it is difficult to comprehensively analyze CVRFs of patients with breast cancer. The purpose of this study was to investigate the CVRFs and arteriosclerotic cardiovascular disease (ASCVD) risk assessment in patients initially diagnosed breast cancer in Southwest China.

\section{Subjects and methods Subjects}

A total of 600 patients diagnosed with breast cancer at the Breast Cancer Center in the First Affiliated Hospital of Chongqing Medical University from January 2014 to December 2019 were included in this retrospective study. Depending on whether menopause had occurred when breast cancer was diagnosed, patients were divided into the premenopausal group $(\mathrm{n}=304)$ and postmenopausal group $(n=296)$. According to whether there was axillary lymph node metastasis (ALNM), patients were divided into metastasis group and a non-metastasis group. Inclusion criteria: (1) female patients with primary breast cancer; (2) patients with clear histological type in pathological report; (3) patients with original medical record in which there were the descriptions of primary tumor, axillary lymph node and distant metastasis. (4) Patients did not receive neo-adjuvant chemotherapy. Exclusion criteria: (1) patients with type I diabetes, nonessential hypertension; (2) patients with a history of malignant cancer at diagnosis or a history of hysterectomy; (3) male patients; (6) patients with distant metastasis at diagnosis; (4) patients with a history of severe hepatic and renal dysfunction; and (5) patients with abnormal thyroid function.

\section{Data collection}

Routine examination data of patients diagnosed with primary breast cancer were collected, including general information, auxiliary inspection information, etc. Fasting blood glucose (FBG), total cholesterol (TC), total triglyceride (TG), high-density lipoprotein cholesterol (HDL-C), low-density lipoprotein cholesterol (LDL-C), lipoprotein (a) (LP (a)) and serum uric acid (SUA) were measured at the Medical Examination Center in the First Affiliated Hospital of Chongqing Medical University. Whether there was the presence of ALNM was collected from the pathological report in the pathology center.

\section{Diagnostic criteria}

Diabetes[9]: fasting glucose $\geq 7.0 \mathrm{mmol} / \mathrm{L}$, randomized glucose $\geq 11.1 \mathrm{mmol} / \mathrm{L}$, or oral glucose tolerance test (OGTT) 2-h glucose $\geq 11.1 \mathrm{mmol} / \mathrm{L}$. Hypertension [10]: Blood pressure $\geq 140 / 90 \mathrm{mmHg}$ in the consultation room (blood pressure in the consultation room was repeatedly measured for three times). Hyperlipidemia [11]: $\mathrm{TC} \geq 6.2 \mathrm{mmol} / \mathrm{L}, \mathrm{TG} \geq 2.3 \mathrm{mmol} / \mathrm{L}, \mathrm{HDL}-\mathrm{C}<1 \mathrm{mmol} / \mathrm{L}$ or LDL-C $\geq 4.1 \mathrm{mmol} / \mathrm{L}$. Hyperuricemia [12]: Fasting blood uric acid levels were observed twice on different days on a normal purine diet, and it is of $>420 \mu \mathrm{mol} / \mathrm{L}$ $(7.06 \mathrm{mg} / \mathrm{dL})$ without gout attack for Chinese adults. Body mass index [13]: The limit for overweight is $\mathrm{BMI}=24$ and that for obesity is $\mathrm{BMI} \geq 28$ for Chinese adults. LP (a) [14]: LP (a) of $\geq 500 \mathrm{mg} / \mathrm{L}$ is used as a powerful ASCVD risk threshold. Menopause [15]: If 12 months after the last menstrual period, there is still no menstrual period, the patient could be clinically diagnosed with menopause after the exclusion of the possibility of pregnancy. The ASCVD risk stratification is shown in Fig. 1.

\section{Statistical analysis}

SPSS 26.0 statistical software was used for statistical analysis. For univariate analysis, graded variables and categorical variables were compared using chi-squared tests, and $p<0.05$ indicated a significant difference. The continuous variable Age, a continuous variable, was normally distributed, and an independent sample test was used for analysis. Variables were represented as means \pm standard deviation (SD). The remaining data were analyzed with descriptive statistics. Age, overweight/obesity, diabetes, hypertension, hyperlipidemia, LP (a), hyperuricemia, ALNM, the place of residence, and the number of children, menstrual status were analyzed by univariate logistic regression analysis to identify the factors affecting ALNM. Then, binary logistic regression analysis was performed to identify factors influencing ALNM in patients with breast cancer. The backward elimination was used to identify variables that were independent risk factors, and $\mathrm{P}<0.1$ was considered to indicate a significant difference.

\section{Results}

\section{The basic characteristics}

Among the 600 patients with primary breast cancer, their age was $(51.43 \pm 10.68)$ years (ranging from 26 to 90 years). A total of 304 patients (50.67\%) were 


\begin{tabular}{|c|c|c|c|}
\hline \multicolumn{4}{|c|}{$\begin{array}{l}\text { People with any two or more of the following risk factors are defined as the high-risk population of ASCVD } \\
\text { extreme risk: ASCVD patient (Including symptomatic PAD patients) } \\
\text { high risk: } \\
\text { (1) DM patient (Age } \geqslant 40 \text { ) } \\
\text { (2) Extremely high levels of individual risk factors, including: (1) LDL-C } \geqslant 4.9 \mathrm{mmol} / \mathrm{L} \\
(190 \mathrm{mg} / \mathrm{dl}) \text { or TC } \geqslant 7.2 \mathrm{mmol} / \mathrm{L} \text { ( } 280 \mathrm{mg} / \mathrm{dl}) ; \text { (2) Grade } 3 \text { hypertension; (3Heavy } \\
\text { smoker (smoke } \geqslant 30 / \mathrm{d})\end{array}$} \\
\hline \multicolumn{4}{|c|}{7 The 10 -year ASCVD risk was assessed according to the table below } \\
\hline \multirow[b]{2}{*}{$\begin{array}{l}\text { risk factor }^{\mathrm{a}} \\
\text { (n) }\end{array}$} & \multicolumn{3}{|c|}{ Serum cholesterol levels were stratified $(\mathrm{mmol} / \mathrm{L})$} \\
\hline & $\begin{array}{c}3.1 \leqslant \mathrm{TC}<4.1 \\
\text { or } 1.8 \leqslant \mathrm{LDL}-\mathrm{C}<2.6\end{array}$ & $\begin{array}{c}4.1 \leqslant \mathrm{TC}<5.2 \\
\text { or } 2.6 \leqslant \mathrm{LDL}-\mathrm{C}<3.4\end{array}$ & $\begin{array}{c}5.2 \leqslant \mathrm{TC}<7.2 \\
\text { or } 3.4 \leqslant \mathrm{LDL}-\mathrm{C}<4.9\end{array}$ \\
\hline \multirow{3}{*}{ No hypertension } & low risk $(<5 \%)$ & low risk $(<5 \%)$ & low risk $(<5 \%)$ \\
\hline & low risk $(<5 \%)$ & low risk $(<5 \%)$ & moderate risk $(5 \% \sim 9 \%)$ \\
\hline & low risk $(<5 \%)$ & moderate risk $(5 \% \sim 9 \%)$ & moderate risk $(5 \% \sim 9 \%)$ \\
\hline \multirow{4}{*}{ Hypertention } & low risk $(<5 \%)$ & low risk $(<5 \%)$ & low risk $(<5 \%)$ \\
\hline & low risk $(<5 \%)$ & moderate risk $(5 \% \sim 9 \%)$ & moderate risk $(5 \% \sim 9 \%)$ \\
\hline & moderate risk $(5 \% \sim 9 \%)$ & high risk $(\geqslant 10 \%)$ & high risk $(\geqslant 10 \%)$ \\
\hline & high risk $(\geqslant 10 \%)$ & high risk $(\geqslant 10 \%)$ & high risk $(\geqslant 10 \%)$ \\
\hline \multicolumn{4}{|c|}{$\begin{array}{l}\text { Risk at } 10 \text { years is moderate level and age }<55 \text { years. Risk at remaining years is } \\
\text { assessed }\end{array}$} \\
\hline $\begin{array}{l}\text { For those who do not meet } \\
\text { below } \\
\begin{array}{ll} & \text { S } \\
& \cdot \mathrm{N} \\
& \mathrm{H} \\
& \mathrm{B} \\
& \cdot \mathrm{S} \\
\end{array}\end{array}$ & $\begin{array}{l}\text { above criteria, the } 10-\mathrm{ye} \\
\mathrm{P} \geqslant 160 \mathrm{mmHg} \text { or } \mathrm{DBP} \geqslant 10 \\
\mathrm{n}-\mathrm{HDL}-\mathrm{C} \geqslant 5.2 \mathrm{mmol} / \mathrm{L}(200 \\
\mathrm{L}-\mathrm{C}<1.0 \mathrm{mmol} / \mathrm{L}(40 \mathrm{mg} / \mathrm{dl}) \\
1 \mathrm{I} \geqslant 28 \mathrm{~kg} / \mathrm{m}^{2} \\
\text { loke }\end{array}$ & $\begin{array}{l}\text { ar ASCVD risk was assess } \\
\mathrm{mg} / \mathrm{dl})\end{array}$ & ed according to the table \\
\hline
\end{tabular}

Fig. 1 ASCVD risk stratification

premenopausal, and 296 (49.33\%) were postmenopausal. A total of 338 patients (56.33\%) lived in the city, and $262(43.67 \%)$ lived in the country. Furthermore, 562 patients $(93.67 \%)$ had a history of childbearing, and $38(6.33 \%)$ had no history of childbearing. 248 patients $(41.33 \%)$ were overweight or obese, and 51 $(8.5 \%)$ had diabetes mellitus. There were 227 patients (37.83\%) with hypertension, 116 (19.33\%) with a combination of hyperlipidemia, and $65(10.83 \%)$ with LP (a) $\geq 500 \mathrm{mg} / \mathrm{L}$. Additionally, 68 patients $(11.33 \%)$ were found to have hyperuricemia (Fig. 2).

\section{Combination of CVRFs in premenopausal and postmenopausal patients with breast cancer in different living environments (city/country)}

There were statistically significant increase in the prevalence of overweight/obesity, type 2 diabetes, and hypertension in the postmenopausal patients in comparison with the premenopausal patients $(p<0.05)$ (Table 1). Rural patients with breast cancer were first diagnosed at a younger age than those living in cities, and the number of rural postmenopausal patients with breast cancer was significantly lower than the number of urban patients $(p<0.05)$ (Table 2$)$.

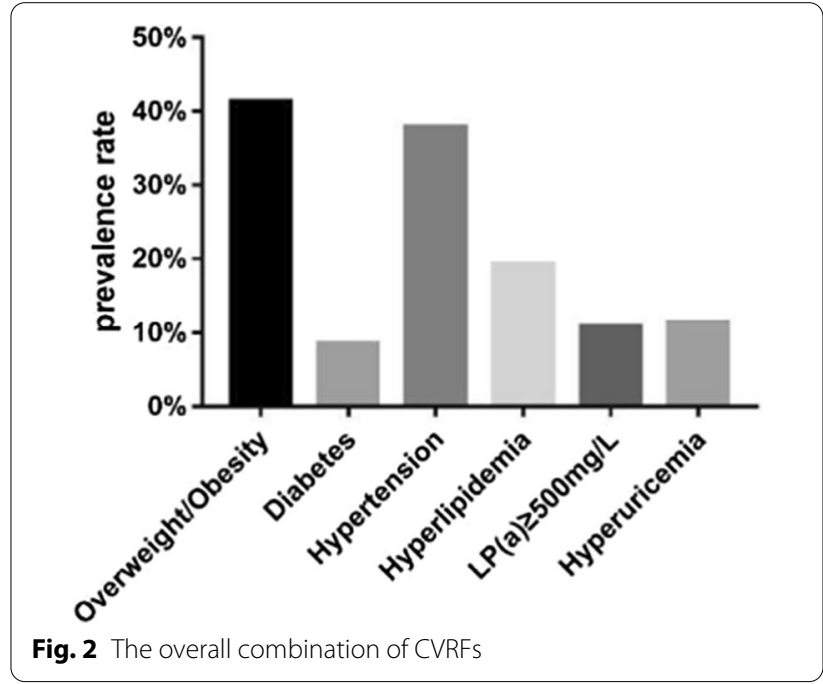

\section{ASCVD risk stratification of patients with breast cancer}

A total of 18 patients (3\%) had an extreme risk of ASCVD, 77 (12.83\%) had a high risk of ASCVD, $62(10.33 \%)$ had a moderate risk of ASCVD in the next 10 years, and 443 (73.84\%) had a low risk (Fig. 3a). ASCVD risk stratification analysis in the premenopausal and postmenopausal patients with breast cancer showed that in the lowrisk group, the number of premenopausal patients was 
Table 1 Characteristics of patients with initial breast cancer [n(\%)]

\begin{tabular}{|c|c|c|c|c|c|}
\hline Characteristics & All $(n=600)$ & $\begin{array}{l}\text { Premenopausal group } \\
(n=304)\end{array}$ & $\begin{array}{l}\text { Postmenopausal group } \\
(n=296)\end{array}$ & $T / x^{2}$ & $p$ \\
\hline Age & $51.43 \pm 10.68$ & $43.72 \pm 6.68$ & $59.360 \pm 7.868$ & -26.220 & 0.000 \\
\hline Overweight/obesity & $248(41.33)$ & $107(35.20)$ & $141(47.64)$ & 9.568 & 0.002 \\
\hline Type 2 diabetes & $51(8.50)$ & $13(4.28)$ & $38(12.84)$ & 14.134 & 0.000 \\
\hline Hypertension & $227(37.83)$ & $80(26.32)$ & $147(49.66)$ & 34.755 & 0.000 \\
\hline Hyperlipidemia & $116(19.33)$ & $50(16.45)$ & $66(22.30)$ & 3.291 & 0.070 \\
\hline LP (a) & & & & 0.594 & 0.441 \\
\hline$\leq 500 \mathrm{mg} / \mathrm{L}$ & $535(89.17)$ & $274(90.13)$ & $261(88.18)$ & & \\
\hline$>500 \mathrm{mg} / \mathrm{L}$ & $65(10.83)$ & $30(9.86)$ & $35(11.82)$ & & \\
\hline Hyperuricemia & $68(11.33)$ & $27(8.88)$ & $41(13.85)$ & 3.686 & 0.055 \\
\hline Axillary lymph node metastasis & $262(48.25)$ & $129(46.07)$ & $133(50.57)$ & 1.099 & 0.294 \\
\hline
\end{tabular}

BMI Body Mass Index, LP (a) Lipoprotein (a)

Table 2 Characteristics of urban and rural patients with initial breast cancer [n(\%)]

\begin{tabular}{|c|c|c|c|c|}
\hline Characteristics & Urban group $(n=338)$ & Rural group $(n=262)$ & $T / X^{2}$ & $p$ \\
\hline Age & $52.59 \pm 11.13$ & $49.94 \pm 9.92$ & 3.027 & 0.003 \\
\hline Postmenopausal & $180(53.25)$ & $116(44.27)$ & 4.761 & 0.029 \\
\hline Overweight/obesity & $131(38.76)$ & $117(44.66)$ & 2.118 & 0.146 \\
\hline Type 2 diabetes & $33(9.76)$ & $18(6.87)$ & 1.588 & 0.208 \\
\hline Hypertension & $137(40.53)$ & $90(34.35)$ & 2.398 & 0.122 \\
\hline Hyperlipidemia & $63(18.64)$ & $53(20.23)$ & 0.239 & 0.625 \\
\hline $\mathrm{LP}(\mathrm{a})$ & & & 0.183 & 0.669 \\
\hline$\leq 500 \mathrm{mg} / \mathrm{L}$ & $303(89.64)$ & $232(88.55)$ & & \\
\hline$>500 \mathrm{mg} / \mathrm{L}$ & $35(10.36)$ & $30(11.45)$ & & \\
\hline Hyperuricemia & $9(2.66)$ & $6(2.29)$ & 0.084 & 0.772 \\
\hline Axillary lymph node metastasis & $140(41.42)$ & $122(46.56)$ & 3.050 & 0.081 \\
\hline Missing & 27 (Of the total) & 30 (Of the total) & & \\
\hline
\end{tabular}

BMI Body Mass Index, LP (a) Lipoprotein (a)

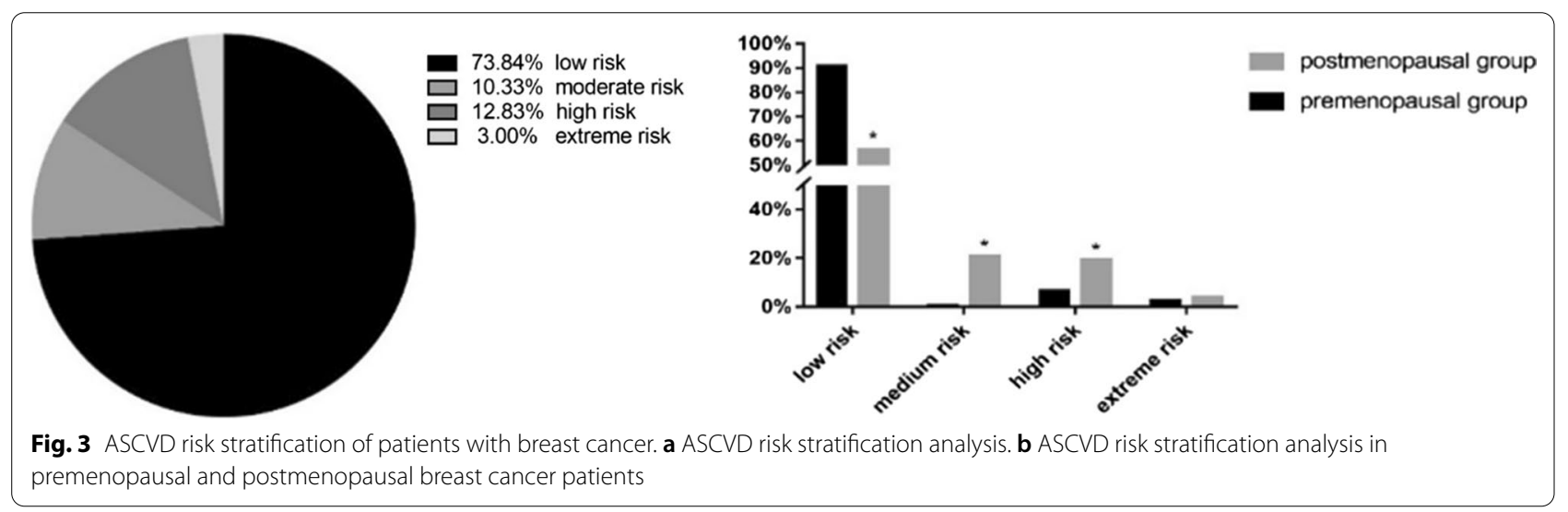

significantly higher than the number of postmenopausal number of postmenopausal patients in the moderate-risk patients $(p<0.05)$. There were significant increase in the 
and high-risk groups than the number of premenopausal patients $(p<0.05)$ (Fig. 3b).

\section{Correlation analysis of CVRFs and ALNM in patients with breast cancer}

Univariate and multivariate analyses of ALNM in patients with breast cancer were shown in Table 3. Univariate logistic analysis showed that in addition to the place of residence, the number of children and LP (a) of $\geq 500 \mathrm{mg} / \mathrm{L}$ were significantly associated with ALNM $(p<0.1)$. Binary logistic regression analysis showed that the independent influencing factors for ALNM were the place of residence $(p=0.087)$, number of children $(p=0.061)$ and LP $(\mathrm{a}) \geq 500 \mathrm{mg} / \mathrm{L}(p=0.080)$. Further analysis showed that patients with breast cancer combined with LP (a) level of $\geq 500 \mathrm{mg} / \mathrm{L}$ were more likely to have ALNM than breast cancer patients with LP (a) levels $<500 \mathrm{mg} / \mathrm{L}$ op to 0.63 times. Patients living in rural areas were more likely to have ALNM than those living in cities up to 0.74 times. For each additional child, the risk of ALNM was 1.25 times higher.

\section{Discussion}

With the increasing incidence of breast cancer and the increasing long-term survival, CVD has become the leading cause of death in patients with breast cancer. Breast cancer and CVD have many common risk factors, and they affect each other. Additionally, chemotherapy, radiotherapy and endocrine therapy further affect the cardiovascular health of patients with breast cancer. Therefore, it is necessary to know the combination of CVRFs in patients with breast cancer diagnosed for the first time. The early management and intervention of CVD in breast cancer patients is beneficial.

CVD is increasingly recognized as an important factor affecting the survival rate and quality of life of patients with breast cancer $[16,17]$. Patients with breast cancer have significantly higher risks of CVD than the healthy controls [18]. Among the 600 patients in our study, the proportion of adult female patients with T2DM is lower than that of female patients without T2DM [23]. This may be related to the exclusion of patients who had received medication for diabetes before the diagnosis of breast cancer. Additionally, oral glucose tolerance test (OGTT) screening has not been performed on patients with normal fasting blood glucose (FBG) levels, and occult diabetes and prediabetes are often missed. However, the proportion of postmenopausal patients with breast cancer and T2DM is still higher than that of patients with DM in China, which is worthy of attention [19]. The prevalence of DM is increased with age. Patients with early T2DM will develop hyperinsulinemia due to insulin resistance. The insulin/insulin receptor (IR) signaling pathway plays an important role in breast cancer progression by stimulating the RAS/RAF/MAPK kinase/ ERK cascade in breast tissues, which results in tumor cell proliferation, survival and migration [20, 21]. In our study, the prevalence of overweight/obesity in postmenopausal patients with breast cancer is significantly higher than that in the premenopausal patients. This is consistent with the findings of Marian L Neuhouser et al., they find that the presence of overweight or obesity increases the risk of breast cancer in postmenopausal women [19]. Fat and inflammation promote the progression of breast cancer, and persistently high estrogen levels increase the risk of breast cancer. Overweight/obese and T2DM individuals have a large amount of fat accumulation, and adipose tissue can produce inflammatory factors and synthesize endogenous estrogen [22]. Therefore, special attention should be paid to active breast cancer screening in postmenopausal women with overweight/obesity and T2DM.

Table 3 Multivariate analysis of factors related to axillary lymph node metastasis in patients with breast cancer

\begin{tabular}{|c|c|c|c|c|c|c|}
\hline \multirow[t]{2}{*}{ Items } & \multicolumn{2}{|c|}{ Univariate } & \multirow[t]{2}{*}{$p$-values } & \multicolumn{2}{|c|}{ Multivariate } & \multirow[t]{2}{*}{$p$-values } \\
\hline & OR & $95 \% \mathrm{Cl}$ & & OR & $95 \% \mathrm{Cl}$ & \\
\hline Age & 1.012 & $0.996-1.028$ & 0.145 & 1.006 & $0.981-1.032$ & 0.632 \\
\hline Place of residence & 0.738 & $0.525-1.038$ & 0.081 & 0.735 & $0.516-1.046$ & 0.087 \\
\hline Number of children & 1.279 & $1.014-1.613$ & 0.038 & 1.250 & $0.990-1.578$ & 0.061 \\
\hline Menstrual status & 0.835 & $0.596-1.170$ & 0.295 & 0.951 & $0.568-1.590$ & 0.847 \\
\hline Overweight/obesity & 1.082 & $0.769-1.524$ & 0.650 & & & \\
\hline Diabetes & 1.065 & $0.585-1.940$ & 0.836 & & & \\
\hline Hypertension & 0.905 & $0.641-1.278$ & 0.570 & & & \\
\hline Hyperlipidemia & 1.155 & $0.757-1.763$ & 0.504 & & & \\
\hline $\mathrm{LP}(\mathrm{a}) \geq 500 \mathrm{mg} / \mathrm{L}$ & 0.578 & $0.332-1.008$ & 0.053 & 0.603 & $0.342-1.063$ & 0.080 \\
\hline Hyperuricemia & 0.575 & $0.186-1.781$ & 0.338 & & & \\
\hline
\end{tabular}


In the present study, the prevalence of hypertension in patients with breast cancer is $27.2 \%$, which is higher than that in Chinese adult women [23]. Breast cancer and hypertension share a common pathophysiological pathway, which is due to that inflammation that induces the occurrence of cancer may also induce hypertension [24]. It may be linked to the blocking and altering of apoptosis by hypertension [25]. However, pathways involved in the relationship between hypertension and breast cancer are still unclear [26]. In our study, the prevalence of hypertension in postmenopausal patients with breast cancer is higher than that in premenopausal women, and the prevalence in China is also higher than other Asian countries (30.60\%)[27]. Our results are consistent with the increasing prevalence of hypertension with increasing age, and it may also be related to high salt intake in Southwest China.

The 10-year ASCVD risk assessment form is used to predict the 10-year ASCVD risk of the healthy controls in China based on comprehensive indicators, such as age, DM, a history of ASCVD and blood lipid profiles [11]. Our results have showed that most patients with initially diagnosed breast cancer have a low risk of ASCVD. According to different menopausal statuses, there are more moderate-risk and high-risk patients among postmenopausal patients. In this prediction, age is a non-modifiable factor, and the ASCVD risk gradually increases with increasing age. At the same time, the subsequent treatment of cancer patients will further increase the burden on the cardiovascular system. Therefore, as the number of cancer patients increases, it may be more useful to establish predictive cardiovascular risk scores for cancer patients receiving treatment. Therefore, the risk of ASCVD in postmenopausal women should be evaluated when they are initially diagnosed breast cancer.

ALNM is the most common type of metastasis in breast cancer, and it is a major factor in assessing the prognosis. Our study has showed that the place of residence (rural), number of children $(\geq 1)$ and LP (a) level $(\geq 500 \mathrm{mg} / \mathrm{L})$ may be risk factors for breast cancer ALNM. A survival study of 18,133 women with malignant tumors in southern China has showed that the prognosis of urban women with malignant tumors is better than that of rural women [28]. Women who had not been pregnant or given birth have a better prognosis than women who have been pregnant or given birth, and some important risk factors for breast cancer are related to fertility [29]. These findings are consistent with our research results. The causes of the poor prognosis in rural women may be related to the fact that they generally have more children, limited access to adequate medical resources and less opportunities to undergo early breast cancer screening. The data supporting the idea that an LP (a) level of $\geq 500 \mathrm{mg} / \mathrm{L}$ can increase the risk of ALNM to affect the prognosis of breast cancer patients are limited, and no conclusion can be drawn yet. In the present study, we have showed that patients with breast cancer combined with an LP (a) level of $\geq 500 \mathrm{mg} / \mathrm{L}$ may have a higher risk of ALNM. A study has investigated LP (a) levels in patients with breast cancer [30] and it has showed that there is a highly significant correlation between LP (a) level and development and progression of breast cancer. A prospective study [31] has suggested that LP (a) levels are positively correlated with the risks of breast cancer and myocardial infarction. LP (a) may play an important role in the diagnosis and treatment of breast cancer. This is consistent with our findings in this study. The 2016 European Society of Cardiology (ESC)/European Atherosclerosis (EAS) Guidelines for the Management of Dyslipidemia have indicated that people with LP (a) levels of $\geq 500 \mathrm{mg} / \mathrm{L}$ have a high risk for ASCVD. And LP (a) level is also strongly correlated with the severity of coronary artery disease. Therefore, attention should be paid to the LP (a) level in patients with breast cancer, which plays a very important role in the prognosis of breast cancer.

\section{Conclusion}

In conclusion, postmenopausal patients have more CVRFs and higher risks of ASCVD than premenopausal patients among patients initially diagnosed with breast cancer. There is a correlation between CVRFs and ALNM in patients with breast cancer.

\section{Abbreviations}

FBG: Fasting blood glucose; TC: Total cholesterol; TG: Total triglyceride; HDL-C: High-density lipoprotein cholesterol; LDL-C: Low-density lipoprotein cholesterol; SUA: Serum uric acid; CVRFs: Cardiovascular risk factors; ASCVD: Arteriosclerotic cardiovascular disease; ALNM: Axillary lymph node metastasis; OGTT: Oral glucose tolerance test; SD: Standard deviation; IR: Insulin receptor; ESC: European Society of Cardiology; EAS: European Atherosclerosis.

\section{Acknowledgements \\ Dr. Lingquan Kong and Dr. Shengchun Liu of the Department of Endocrine and Breast Surgery are acknowledged for their useful suggestions and gener- ous help.}

\section{Authors' contributions}

We declare that all the listed authors have participated actively in the study and all meet the requirements of the authorship. Dr. ZYD and FZ designed the study and wrote the protocol, Dr. QJH and ZJL performed research/study, Dr. SYC and TX managed the literature searches and analyses, Dr. JX and CHZ undertook the statistical analysis, Dr. ZYD and XLZ wrote the first draft of the manuscript. All authors read and approved the final manuscript.

\section{Funding \\ None.}

Availability of data and materials

The datasets used or analyzed during the current study are available from the corresponding author on reasonable request. 


\section{Declarations}

Ethics approval and consent to participate

This study is approved by the Ethics Committee of The First Affiliated Hospital of Chongqing Medical University. Signed informed consent were also obtained from all participants.

\section{Consent for publication}

Written consent were obtained.

\section{Competing interests}

The authors declare that they have no competing interests.

\section{Author details}

'Department of Cardiology, The First Affiliated Hospital of Chongqing Medical University, 1 Youyi Road, Yuzhong District, Chongqing 400000, China. ${ }^{2}$ School of Public Health and Management, Research Center for Medicine and Social Development, Collaborative Innovation of Chongqing Medical University, Chongqing 400000, China. ${ }^{3}$ Department of Endocrine and Breast Surgery, The First Affiliated Hospital of Chongqing Medical University, Chongqing 400000, China.

Received: 15 June 2021 Accepted: 2 August 2021

Published online: 12 August 2021

\section{References}

1. Therapy CEGoMMoDiBCPwE. China expert consensus on the management of dyslipidemia in postmenopausal patients with early-stage breast cancer. Chin J Oncol. 2017;39:72-7.

2. Ying Z, Chun-Xiao WU, Minlu Z. The epidemic and characteristics of female breast cancer in China. China Oncol. 2013;23:561-9.

3. Chan DS, Norat T. Obesity and breast cancer: not only a risk factor of the disease. Curr Treat Opt Oncol. 2015;16:22.

4. Tamirisa N, Lin H, Shen Y, Shaitelman SF, Sri Karuturi M, Giordano SH, et al. Association of chemotherapy with survival in elderly patients with multiple comorbidities and estrogen receptor-positive. Node Positive Breast Cancer JAMA Oncol. 2020;6(10):1548-54.

5. Rodriguez LA, Bradshaw PT, Parada H, Khankari NK, Wang T, Cleveland RJ, et al. Diabetes and cardiovascular disease mortality among a populationbased cohort of women with and without breast cancer. Cancer Causes Control. 2020;31(5):517-24.

6. Knisely JPS, Henry SA, Saba SG, Puckett LL. Cancer and cardiovascular disease. Lancet. 2020;395(10241):1904.

7. Harake D, Franco Vi Fau-Henkel JM, Henkel Jm Fau-Miller TL, Miller TI Fau-Lipshultz SE, Lipshultz SE. Cardiotoxicity in childhood cancer survivors: strategies for prevention and management. Future Cardiol. 2012;8:647-70.

8. Okwuosa TM, Anzevino S, Rao R. Cardiovascular disease in cancer survivors. Postgrad Med J. 2017;93:82-90.

9. King H. WHO and the International Diabetes Federation: regional partners. Bull World Health Organ. 1999;77:954.

10. Williams B, Mancia G, Spiering W, Agabiti Rosei E, Azizi M, Burnier M, et al. 2018 ESC/ESH Guidelines for the management of arterial hypertension: the Task Force for the management of arterial hypertension of the European Society of Cardiology and the European Society of Hypertension. J Hypertens. 2018;36:1953-2041.

11. Zhu JR, Zhao S, Zhao D, Li J. Guidelines for the prevention and treatment of dyslipidemia in Chinese adults (2016 Revision). Chin Circ J. 2016;16:15-35.

12. Chinese Endocrine Society. Guidelines for the diagnosis and treatment of hyperuricemia and gout in China (2019). Chin J Endocrinol Metab. 2020;1:1-13.
13. Wgooi C. Guidelines for the prevention and control of overweight and obesity in Chinese adults (excerpts). Acta Nutrimenta Sinca. 2004;26:1-4.

14. Catapano Al Fau-Graham I, Graham I Fau-De Backer G, De Backer G Fau-Wiklund O, Wiklund O Fau-Chapman MJ, Chapman Mj Fau-Drexel H, Drexel H Fau-Hoes AW, et al. 2016 ESC/EAS guidelines for the management of dyslipidaemias. Eur Heart J. 2016;37:2999-3058.

15. Qi Y. 2018 Chinese guideline on menopause management and menopause hormone therapy. Med J Peking Union Med Coll Hosp. 2018:9:512-25

16. Gernaat SAM, Ho PJ, Rijnberg N, Emaus MJ, Baak LM, Hartman M, et al. Risk of death from cardiovascular disease following breast cancer: a systematic review. Breast Cancer Res Treat. 2017;164:537-55.

17. Hooning MJ, Aleman BM, van Rosmalen AJ, Kuenen MA, Klijn JG, van Leeuwen FE. Cause-specific mortality in long-term survivors of breast cancer: a 25-year follow-up study. Int J Radiat Oncol Biol Phys. 2006:64:1081-91.

18. Armenian SH, Xu L, Ky B, Sun C, Farol LT, Pal SK, et al. Cardiovascular disease among survivors of adult-onset cancer: a community-based retrospective cohort study. J Clin Oncol. 2016;34:1122-30.

19. Neuhouser ML, Aragaki AK, Prentice RL, Manson JE, Chlebowski R, Carty $\mathrm{CL}$, et al. Overweight, obesity, and postmenopausal invasive breast cancer risk: a secondary analysis of the women's health initiative randomized clinical trials. JAMA Oncol. 2015;1:611-21.

20. Papa V, Pezzino V Fau-Costantino A, Costantino A Fau-Belfiore A, Belfiore A Fau-Giuffrida D, Giuffrida D Fau-Frittitta L, Frittitta L Fau-Vannelli GB, et al. Elevated insulin receptor content in human breast cancer. J Clin Invest. 1990:86:1503-10.

21. Ward CW, Lawrence MC. Ligand-induced activation of the insulin receptor: a multi-step process involving structural changes in both the ligand and the receptor. Bioessays. 2009;31:422-34.

22. Zhao S Fau-Chlebowski RT, Chlebowski Rt Fau-Anderson GL, Anderson Gl Fau-Kuller LH, Kuller Lh Fau-Manson JE, Manson Je Fau-Gass M, Gass $M$ Fau-Patterson $\mathrm{R}$, et al. Sex hormone associations with breast cancer risk and the mediation of randomized trial postmenopausal hormone therapy effects. Breast Cancer Res. 2014;26;16(2):R30.

23. Shengshou GR, Liu L, Zhu M, Wang W, Wang Y, Wu Z, Li H, Gu D, Yang Y, Zheng Z, Chen W. Summary of China's cardiovascular report 2018. Chin Circ J. 2019:34:6-17.

24. Balkwill F, Charles Ka Fau-Mantovani A, Mantovani A. Smoldering and polarized inflammation in the initiation and promotion of malignant disease. Cancer Cell. 2005;7:211-7.

25. Hamet P. Cancer and hypertension. An unresolved issue. Hypertension. 1996;28:321-4

26. Largent JA, McEligot AJ, Ziogas A, Reid C, Hess J, Leighton N, Peel D, Anton-Culver $\mathrm{H}$. Hypertension, diuretics and breast cancer risk. J Hum Hypertens. 2006;20:727-32.

27. Noh HM, Song YM, Park JH, Kim BK, Choi YH. Metabolic factors and breast cancer risk in Korean women. Cancer Causes Control. 2013;24:1061-8.

28. Gong WLS, Hu R, Wang H, Pan J, Fei F, He Q, Yu M. Analysis of survival rate of breast, cervical, and ovarian cancer patients during 2005-2010 in Zhejiang province, China. Chin J Prevent Med. 2014:48:366-9.

29. Wang SWY, Rong T. Reproductive history and prognosis in patients with operable breast cancer. Tumor. 1999;19:75-7.

30. Sharma AGB, Gupta N, Chakraborty B. Lipoprotein (a) plasma levels and risk of breast cancer. Hellenic J Surg. 2015;87:298-302.

31. Katzke VASD, Johnson T, Kühn T, Kaaks R. Blood lipids and lipoproteins in relation to incidence and mortality risks for CVD and cancer in the prospective EPIC-Heidelberg cohort. BMC Med. 2017;15:218.

\section{Publisher's Note}

Springer Nature remains neutral with regard to jurisdictional claims in published maps and institutional affiliations. 